\title{
INTERthesis
}

\section{TRANSFORMAÇÕES NO SISTEMA TRADICIONAL DE ROÇA ITINERANTE NA MATA ATLÂNTICA DO LITORAL SUL BRASILEIRO}

\author{
Nicole Rodrigues Vicente ${ }^{1}$
}

Alfredo Celso Fantini ${ }^{2}$

\section{Resumo:}

Este artigo visa compreender as mudanças ocorridas no sistema tradicional de roça itinerante no litoral de Santa Catarina ao longo das últimas quatro décadas. A pesquisa foi desenvolvida junto a agricultores tradicionais moradores de duas microbacias hidrográficas do município de Biguaçu-SC. A unidade amostral foi a propriedade onde reside 0 informante-chave, selecionado via Bola-de-Neve. Foram conduzidas entrevistas semiestruturadas, observações participante e turnês-guiadas para coleta de dados. A análise de dados se deu por meio do software Atlas.ti, de estatística descritiva e análise multivariada de Componentes Principais. Os dados foram interpretados com base na linha histórica de ocorrência. A pesquisa diagnosticou que o manejo realizado pela população local se fundamenta na condução periódica de cultivos agrícolas e florestais, num sistema de rotação com períodos de pousio. As principais culturas agrícolas utilizadas eram a mandioca, a banana, o milho, o café e a cana-de-açúcar, mas atualmente apenas a mandioca tem forte expressão. Para todas as fases de desenvolvimento do manejo os agricultores apresentam conhecimentos específicos de leitura da paisagem e da dinâmica florestal. Mudanças nas políticas agrícolas e gestão das florestas nativas têm afetado diretamente o sistema de roça itinerante nas microbacias estudadas. A população local apresenta relação intrínseca com os recursos florestais nativos devendo ter seu modo de vida respeitado e seu sistema tradicional valorizado.

Palavras-chave: Roça-de-toco. Agricultura familiar. Florestas secundárias. Populações tradicionais. Ecologia histórica.

\section{INTRODUÇÃO}

As principais bases para compreender as respostas das paisagens perante a influência das ações humanas provêm do arcabouço teórico da ecologia histórica, bem como para analisar as transformações humanas resultantes das transformações na paisagem (LUNT; SPOONER, 2005; BALÉE, 2006). Na complexidade da paisagem, os

\footnotetext{
1 Doutoranda em Recursos Genéticos Vegetais e pesquisadora do Núcleo de Florestas Tropicais da Universidade Federal de Santa Catarina, Florianópolis, SC, Brasil. E-mail: nicsrv@gmail.com 2 Doutor em Ciências Florestais pela University of Wisconsin, Madison, EUA. Professor do Departamento de Fitotecnia, Centro de Ciências Agrárias, Laboratório de Ecologia e Manejo de Ecossistemas Florestais da Universidade Federal de Santa Catarina, Florianópolis, SC, Brasil. E-mail: afantini@cca.ufsc.br
}

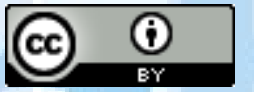


agricultores estão cotidianamente manejando os agroecossistemas e os elementos da biodiversidade a eles associados (BROOKFIELD; PADOCH, 2007). Muitas práticas utilizadas por povos tradicionais estão direcionadas a promoção da heterogeneidade no habitat em nível de paisagem e intensificar o manejo de uso. Essas práticas aumentam tanto a complexidade local quanto a diversidade dos recursos biológicos disponíveis (BERKES et al., 1995; JARVIS et al., 2007). A análise dessas relações entre ser humano e paisagem se fundamenta em ciências como ecologia, geografia, história ambiental, antropologia (SOLÓRZANO et al., 2009), focando principalmente na escala temporal e espacial desta relação. Dessa forma, a interferência humana na paisagem tem apresentado influência dos padrões dinâmicos dos ecossistemas, mas nem sempre em um cenário de degradação (WILLIS et al., 2004), e sim na contribuição desta relação para aumento da diversidade alfa e beta (BALÉE, 1992; 2006).

De acordo com as características étnicas dos povoamentos humanos a interação com a paisagem em que habitam e se relacionam seguem diferentes rumos. Povos caiçaras e quilombolas (ADAMS, 2000a; 2000b; HANAZAKI et al., 2000; HANAZAKI et al., 2006; ADAMS et al., 2013), migrantes europeus (ZUCHIWISHI et al, 2010; MILANESI et al., 2013) e povos indígenas (FLOWERS, et al., 1982; CRIVOS et al., 2007) atuam-na paisagem de formas distintas, mas são influenciadas por suas ações. Por esse motivo a compreensão etnográfica sobre as populações humanas e seus recursos ambientais manejados é uma ferramenta intrínseca para a análise em ecologia histórica (COOMES et al., 2000; CAIRNS, 2007; GARRITY, 2007). A agricultura itinerante, típica dos ecossistemas florestais tropicais, tem sido praticada por populações tradicionais ao redor do mundo, durante séculos, como um meio resiliente de adaptação às condições ambientais impostas por estes ecossistemas complexos (CONKLIN, 1961; BROWN; SCHRECKENBERG, 1998; ADAMS, 2000a; MAZOYER; ROUDART, 2010; VLIET et al., 2012). Estes sistemas agrícola-florestais de roça itinerante, ou agroflorestais, são praticados principalmente por populações indígenas da América Latina, África e Ásia especialmente em regiões montanhosas (SOEDARSONO E HARTANTI, 1995; COLFER et al., 1997; ROUÉ, 2000; MICHON, 2005; CAIRNS, 2007; PADOCH E PINEDO-VASQUEZ, 2010). Apesar do seu potencial para promoção das florestas este sistema tradicional tem sido substituído ao longo dos trópicos por atividades agrícolas com monocultivo que degradam e impactam negativamente o meio ambiente (VLIET et al., 2012).

R. Inter. Interdisc. INTERthesis, Florianópolis, v.11, n.2, p.183-203, Jul./Dez. 2014

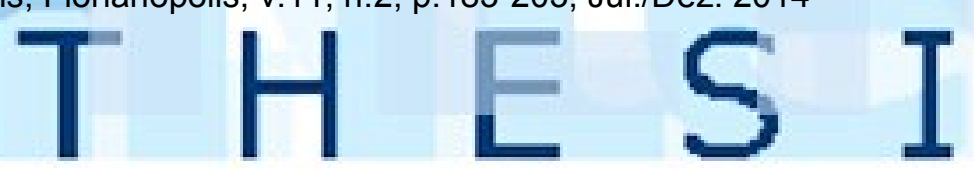


Como agentes de transformação da paisagem, afetando e sendo afetados pelos resultados de suas intervenções, os seres humanos apresentam conexão cultural e social com as o meio em que vivem e atuam (LUNT \& SPOONER, 2005; BALÉE, 2006). Esta visão, associada à ecologia histórica, evidencia que as florestas, tais quais como as conhecemos, aparentemente pristinas, são na verdade o legado de populações antigas. Isto é evidenciado pela presença de espécies- chaves que indicam o histórico ecológico de áreas povoadas, onde a agricultura foi presente (BALÉE, 1992; WILLIS et al., 2004; WILLIS et al., 2004; BALÉE, 2006). O objetivo desta pesquisa foi compreender e estruturar no tempo as mudanças ocorridas que influenciaram as transformações no sistema tradicional de roça itinerante no litoral de Santa Catarina de forma a averiguar a raízes dessas mudanças e sua influência perante à permanência das famílias no campo.

\section{METODOLOGIA}

A pesquisa foi desenvolvida no município de Biguaçu, região litorânea central do estado de Santa Catarina (Figura 1). O município apresenta área $370,87 \mathrm{~km} 2$, com uma população de 58.206 habitantes e densidade demográfica de 156,94 hab/km² (IBGE, 2013). Tomou-se como unidade básica duas Microbacias ${ }^{3}$ do município, a São Mateus e a Fazendas, na localidade de "Três Riachos". Na região da pesquisa a formação florestal predominante é a Floresta Ombrófila Densa (FOD), a qual se estende pela região litorânea do estado e é uma das regiões fitoecológicas do bioma Mata atlântica. Sua distribuição abrange principalmente as áreas montanhosas do litoral do Estado e abrange hoje cerca de $40 \%$ de todo território estadual (VIBRANS et al., 2013).

A pesquisa foi desenvolvida junto a comunidades de pequenos agricultores silvicultores (SIMINSKI; FANTINI, 2007) que habitam a localidade por mais de duas gerações. A população pode ser considerada tradicional com base no conceito utilizado por Diamond (2012) que as classifica como sociedades que vivem sob baixas densidades populacionais, em pequenos grupos tendo sua sobrevivência por meio do cultivo da terra e sendo transformadas em determinado grau pelo contato constante

\footnotetext{
3 "Um conjunto de terras drenadas por um rio e seus afluentes, formada nas regiões mais altas do relevo por divisores de água, onde as águas das chuvas, ou escoam superficialmente formando os riachos e rios, ou infiltram no solo para formação de nascentes e do lençol freático" (BARRELLA, 2001).
}

R. Inter. Interdisc. INTERthesis, Florianópolis, v.11, n.2, p.183-203, Jul./Dez. 2014

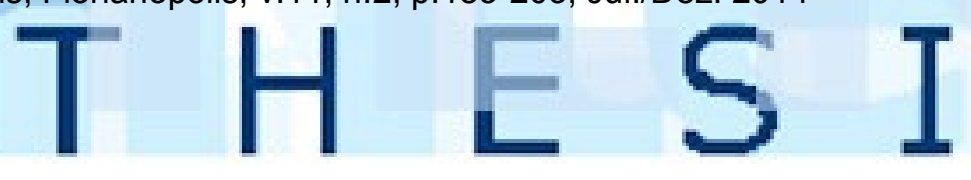


com as sociedades modernas. A população local apresenta raízes fortes da cultura camponesa associada às regiões de floresta tropical, e dependem financeira e culturalmente do manejo da floresta em áreas declivosas. Por volta do ano de 1816 apareceram os primeiros povoados na localidade de "Três Riachos" (IBGE, 2013a) .

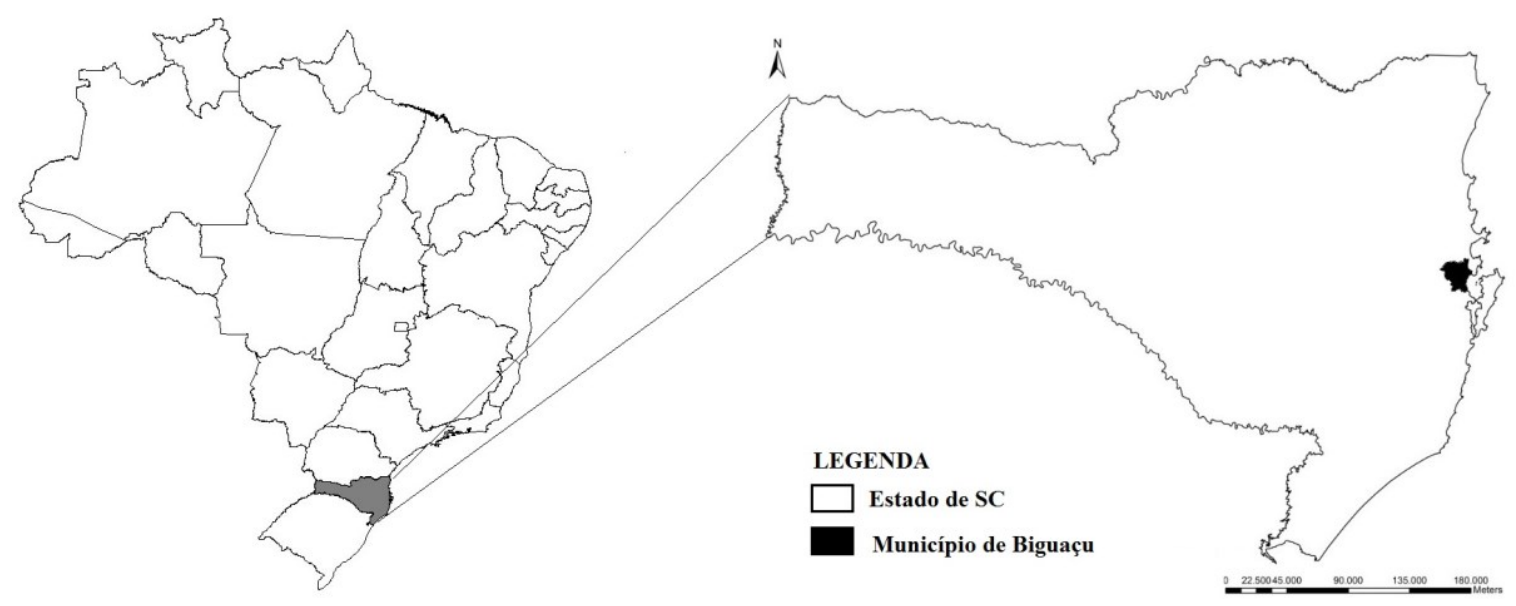

Figura 1. Localização do Município de Biguaçu, no Estado de Santa Catarina, Região Sul brasileira

A unidade amostral foi o estabelecimento rural onde reside o informante-chave, cujo perfil foi intencionalmente selecionado (TONGCO, 2007). Os informantes foram selecionados via "Bola-de-Neve" (BERNARD, 1994) enquadrando-se no seguinte perfil: ser pequeno produtor rural; residir na localidade há pelo menos 30 anos; manejar áreas de populações de floresta nativa em seu estabelecimento ou tê-las manejado dentro dos últimos 30 anos.

Os dados foram coletados durante os anos de 2010, 2011 e 2012, quando conduzidas entrevistas semiestruturadas (ALEXIADES, 1996; VIETLER, 2001) visando levantar informações sobre o sistema tradicional e atual de roça itinerante, e as transformações ao longo do tempo no passado - de 1970 a 1999; e no presente - de 2000 até o presente momento. Foram realizadas "Observações Participante" (VIETLER, 2001) e "Turnês-guiadas" (MARTIN, 2007) em seis propriedades de informantes-chave.

Após a sistematização dos dados qualitativos por meio do software Atlas.ti (7.0, 1993-2013) procedeu-se à análise desses por meio de estatística descritiva apresentando médias, frequências relativas, absolutas e descrição etnográfica com base nas falas dos informantes. Foi realizada análise multivariada de Componentes Principais (PCA) averiguando a contribuição das práticas de manejo na diferenciação do sistema praticado no período das décadas de 70 - 90 e nos anos 2000. Esta análise

R. Inter. Interdisc. INTERthesis, Florianópolis, v.11, n.2, p.183-203, Jul./Dez. 2014

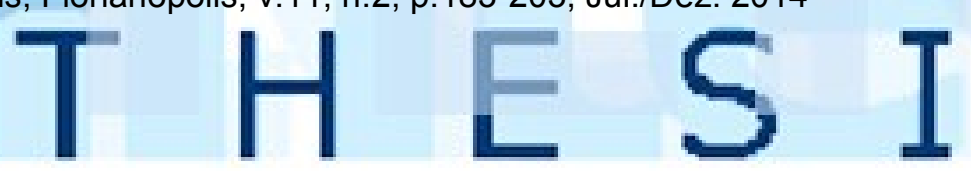


foi realizada utilizando-se o Software Past $(2.12,2009-2011)$. Os dados foram interpretados com base na linha histórica de ocorrência.

\section{RESULTADOS E DISCUSSÃO}

\subsection{A POPULAÇÃO LOCAL E O SISTEMA DE MANEJO}

A população estudada compreendeu 24 unidades familiares, onde foram entrevistadas 39 pessoas, 26 homens e 13 mulheres, com média de idade de 60 e 61 anos, respectivamente. Os agricultores que colaboraram como informantes neste trabalho estão distribuídos em três comunidades rurais: Fazenda de Dentro (Microbacia Fazendas), Canudos e São Mateus (Microbacia São Mateus). Todos apresentam o mesmo histórico familiar: são filhos e netos de agricultores que nasceram na região, compondo assim a terceira geração de habitantes da localidade. Por esse motivo, podem ser considerados como população tradicional (DIAMOND, 2012).

As atividades de manejo praticadas pela população local nas encostas declivosas das microbacias se fundamentam na supressão florestal para obtenção de lenha e uso do solo fertilizado que é fruto tanto do pousio como das cinzas resultantes da queima da biomassa. As famílias locais apresentam relação direta com a floresta sendo esta o elemento-chave do modo de vida destes agricultores silvicultores. Suas atividades agrícolas estão diretamente relacionadas ao componente florestal que provê ao sistema utilizado tanto a fertilidade necessária para cultivos anuais/bianuais/semiperenes, quanto para obtenção de produtos madeireiros, como madeira para usos domésticos e lenha para abastecer os fornos de carvão ou engenhos de farinha.

Grande parte das famílias se dedica hoje à atividade carvoeira como principal fonte de renda (Tabela 1). A frequência da atividade carvoeira é inferior apenas à das famílias com renda proveniente da aposentadoria. Contudo, a produção vegetal de mandioca e banana são atividades rentáveis importantes praticadas por uma pequena parte da população. A produção de hortaliças é praticada primordialmente por famílias da comunidade Canudos, onde o acesso às áreas de várzea é bastante facilitado.

R. Inter. Interdisc. INTERthesis, Florianópolis, v.11, n.2, p.183-203, Jul./Dez. 2014
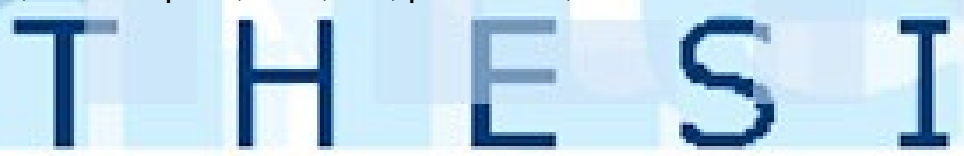
Tabela 1. Indicadores socioeconômicos dos agricultores silvicultores participantes da pesquisa em Três Riachos em Biguaçu-SC

\begin{tabular}{llccccc}
\hline & & \multicolumn{3}{c}{ Comunidade } & Total & $\%$ \\
\cline { 3 - 6 } Parâmetro/classe & Canudos & $\begin{array}{c}\text { Fazenda de } \\
\text { Dentro }\end{array}$ & $\begin{array}{c}\text { São } \\
\text { Matheus }\end{array}$ & \\
\hline $\mathbf{N}^{\circ}$ unidades amostrais & & 6 & 9 & 9 & 24 & - \\
\hline $\mathbf{N}^{\circ}$ informantes & 11 & 14 & 13 & 39 & - \\
\hline Gênero dos informantes & Masculino & 7 & 10 & 9 & 26 & 67 \\
& Feminino & 4 & 4 & 5 & 13 & 30 \\
\hline \multirow{2}{*}{$\begin{array}{l}\text { Atividade principal atual } \\
\text { na Unidade amostral }\end{array}$} & Aposentadoria & 3 & 5 & 6 & 14 & 36 \\
(fonte de renda) & Carvão & 5 & 3 & 4 & 12 & 31 \\
& Banana & 1 & 1 & 2 & 4 & 10 \\
& Eucalipto & 1 & 2 & 2 & 5 & 13 \\
& Olericultura & 3 & 2 & 0 & 2 & 05 \\
& Outras & 0 & 1 & 0 & 4 & 10 \\
\hline Manejo itinerante & No passado & 6 & 5 & 3 & 8 & 21 \\
\hline & No presente & 3 & 5 & 9 & 24 & 100 \\
\hline
\end{tabular}

A produção de carvão vegetal também foi encontrada como a principal atividade das famílias da localidade pelo estudo realizado por Bauer (2012) demonstrando ainda que a aposentadoria também é uma das principais fontes de renda das famílias do local. Já Siminski e Fantini (2004), em estudo no município vizinho, não encontraram práticas voltadas à produção carvoeira, mas sim maior incidência da produção de mandioca, bem como a aposentadoria e os serviços no comércio sendo encontrados também em grande expressão. Ambos os autores encontraram a prática da agricultura itinerante como principal sistema cultural de uso da terra, mas em fase de declínio.

Nas três comunidades aqui analisadas o sistema itinerante também se encontra em declínio sendo que apenas $37 \%$ das famílias ainda o praticam. Percebe-se, ainda, uma maior ênfase no abandono do sistema tradicional na comunidade São Mateus, talvez pela existência de maior fiscalização ambiental, visto a facilidade de acesso. Algumas famílias comercializam produtos in natura como mandioca, banana e hortaliças, principalmente destinados ao CEASA (Central de Abastecimento Sociedade Anônima) da Grande Florianópolis.

R. Inter. Interdisc. INTERthesis, Florianópolis, v.11, n.2, p.183-203, Jul./Dez. 2014

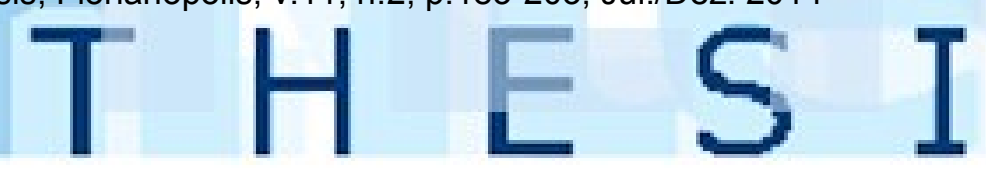


O manejo realizado pela população local se fundamenta na condução periódica e sucessiva de cultivos agrícolas e florestais, num sistema de rotação que inclui períodos de cultivo e pousio. Inicialmente é selecionada uma gleba florestal para supressão que seja de fácil acesso e apresente, visualmente, indivíduos com diâmetro no entorno de $3,0 \mathrm{~cm}$. As principais culturas agrícolas utilizadas eram a mandioca, a banana, o milho, o café e a cana-de-açúcar. Tradicionalmente as espécies florestais utilizadas no sistema eram tanto da mata nativa quanto a bracatinga.

Nos lotes de mata nativa ou de bracatinga, o sistema é iniciado com a roçada seletiva do sub-bosque, para eliminação da vegetação arbustiva de menor diâmetro e da vegetação herbácea, formando assim uma camada de biomassa sobre o solo, mais suscetível ao fogo, que será usado para limpar a superfície do solo e proporcionar fácil locomoção dentro do lote. Alguns agricultores utilizam o fogo antes da derruba outros o utilizam após a derrubada. O fogo é utilizado como uma ferramenta de limpeza da área e produção de fertilidade por meio das cinzas.

Posteriormente ao fogo, que se alastra rápida e ligeiramente pelo lote, é então feita a supressão da gleba. Os fustes permanecem sobre o solo por um período de aproximadamente um a dois meses, no intuito de promover a desidratação da madeira, necessária para obtenção de lenha com teor aceitável de umidade visando uso no forno de carvão ou como lenha nos engenhos. Após o período de desidratação da madeira é realizado o seccionamento dos troncos em pequenas toras com comprimento de aproximadamente um metro. Após empilhamento da lenha os agricultores realizam periodicamente o seu transporte.

Na fase agrícola no sistema tradicional as práticas de condução da roça (Figura 2) incluíam o plantio de espécies florestais desejadas como ingá (Inga edulis e Inga virescens); a condução da regeneração natural proveniente do banco de sementes depositado no solo e do rebrote dos tocos remanescentes após a supressão da floresta. Dessa forma as áreas suprimidas eram conduzidas à regeneração ao longo do processo de cultivo agrícola. Grande parte dos agricultores mantém a roça com capina seletiva das ervas espontâneas, preservando seletivamente a regeneração natural da floresta por meio da germinação do banco de sementes presente no solo ou do rebrote dos tocos. Quando utilizada a bracatinga (ou maracatinga, como é localmente conhecida), ela é semeada uma única vez e conduzida após manejo do fogo nos demais ciclos de uso da área. Pequena parte dos agricultores não realiza atividades específicas após plantio das culturas no lote suprimido, apenas mantém a 
área "limpa", abandonando-a depois da colheita das culturas anuais para regenerar em pousio.

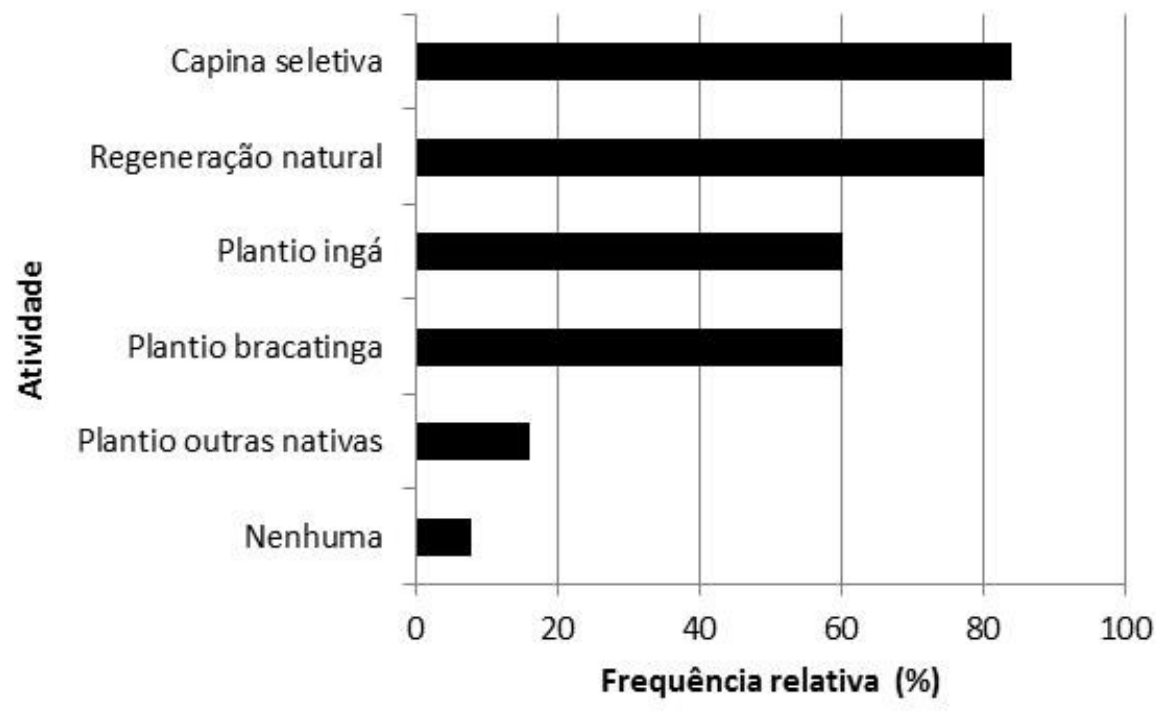

Figura 2. Estratégias de condução da roça itinerante após plantio de culturas agrícolas por agricultores familiares da Microbacia do Rio dos Três Riachos, Biguaçu-SC

Ao praticar tais estratégias os agricultores locais atuam de forma a promover a regeneração florestal o mais breve possível. Guariguata e Ostertag (2001), ao analisar as mudanças das características estruturais e funcionais de florestas secundárias em regeneração, apontam que seu "poder regenerativo" só será alto caso existam no entorno "fontes de propágulo e que a intensidade de uso da terra antes do abandono não seja severa". Sendo assim, a prática promovida pela população local de manejo da regeneração ou introdução de espécies, tende a recompor o ecossistema florestal rapidamente, favorecendo tanto a manutenção da cobertura vegetal na propriedade (de interesse do ponto de vista conservacionista) quanto à produção de lenha e a recuperação do solo (de interesse do ponto de vista produtivista).

O sucesso no processo de regeneração é um dos principais objetivos das populações tradicionais que manejam áreas de floresta no sistema de roças itinerantes. Para que isso possa ocorrer, a floresta deve ter seu potencial de resiliência preservado e para isso a contínua entrada de propágulos provenientes de fontes próximas às áreas suprimidas é fundamental. Assim também o é, a manutenção da composição e riqueza nas diferentes guildas, ou seja, nos diferentes grupos funcionais, promovendo atração à fauna dispersora e manutenção da dinâmica sucessional entre estratos e estágios de regeneração (TABARELLI E MONTOVANI, 1999; ROCHA-SANTOS E TALORA, 2012; NAKAGAWA, et al., 2013).

R. Inter. Interdisc. INTERthesis, Florianópolis, v.11, n.2, p.183-203, Jul./Dez. 2014

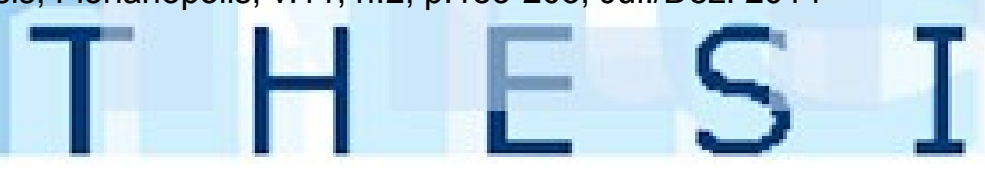




\subsection{A TRANSFORMAÇÃO AO LONGO DO TEMPO}

As famílias agricultoras que praticam atividade silvicultural nas microbacias estudadas apresentam complexa fonte de influências sobre o sistema de manejo que promovem. O histórico de vida e a base de transformações ocorridas ao longo dos últimos 40 anos têm sido fatores decisivos na manutenção ou abandono do sistema tradicional de roça itinerante. As mudanças ocorridas ao longo das últimas décadas (Figura 3) trouxeram algumas dificuldades perante as quais muitas famílias locais não conseguiram se adaptar ao longo do tempo. Tanto os cultivos utilizados foram sendo substituídos, quanto às estratégias de cultivo da terra foram sendo modificadas.

\begin{tabular}{|l|lll|}
\hline \multicolumn{3}{|c}{ Elementos que geraram mudanças no modo de vida da população rural } \\
\hline
\end{tabular}

Figura 3. Linha do tempo dos eventos condutores de mudanças no sistema de roça itinerante ao longo das últimas quatro décadas na localidade Três Riachos, Biguaçu-SC

As mudanças nas políticas e gestão das florestas pelo governo federal, via legislação ambiental, têm afetado diretamente o modo de vida e o sistema de uso da terra nas microbacias estudadas. Essas mudanças tornam-se nítidas ao analisarmos as fontes de renda das quais as famílias sobrevivem hoje (de 2000 até 2010) e sobreviviam no passado (de 1970 a 1999) (Figura 4). No passado as atividades que proviam renda às famílias locais estavam mais diretamente relacionadas aos produtos provenientes da roça (milho, feijão, lenha, açúcar e banana), o que se apresenta R. Inter. Interdisc. INTERthesis, Florianópolis, v.11, n.2, p.183-203, Jul./Dez. 2014
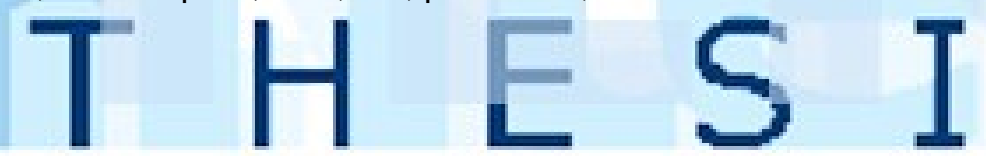
diferente no momento atual, pois as fontes estão mais diretamente ligadas a serviços, aposentadoria e outras atividades agrícolas.

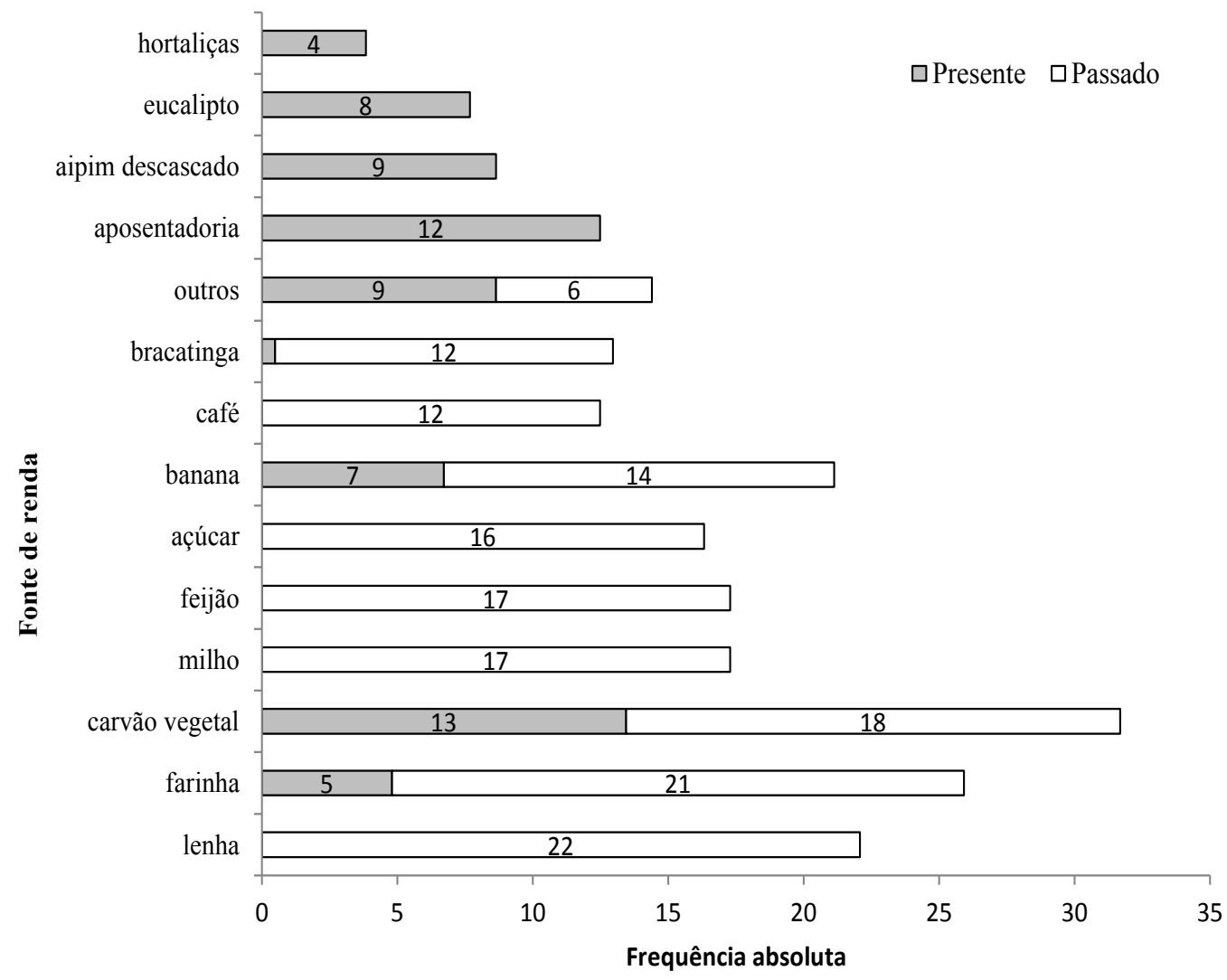

Figura 4. Frequência relativa de informantes-chave envolvidos nas diferentes atividades econômicas como fonte de renda na pequena propriedade, nos momentos presente (após ano de 2000) e passado (de 1970 até o ano 2000), no município de Biguaçu-SC

O que se evidencia é que essas fontes de renda têm se transformado com o passar dos anos. Há 30-40 anos toda a comunidade tinha engenhos de açúcar e cultivava pastagens para alimentar o gado, que era a principal força motora para "tocar" os engenhos no processamento da cana-de-açúcar (moenda). Por esse motivo, tanto a floresta para produção de lenha quanto a pastagem eram elementos fundamentais do sistema. Com o tempo também a produção de café, umas das atividades principais no passado, deixou de existir e deu espaço para cultivos da mandioca, cana-de-açúcar e posteriormente para produção de carvão vegetal. Com as mudanças nas atividades econômicas as transformações na paisagem foram paulatinamente sendo percebidas. Para alguns, a paisagem era composta principalmente por pastagens, como resultado da exploração intensiva das florestas sem a manutenção de longos períodos de pousio ou plantios florestais, como

R. Inter. Interdisc. INTERthesis, Florianópolis, v.11, n.2, p.183-203, Jul./Dez. 2014
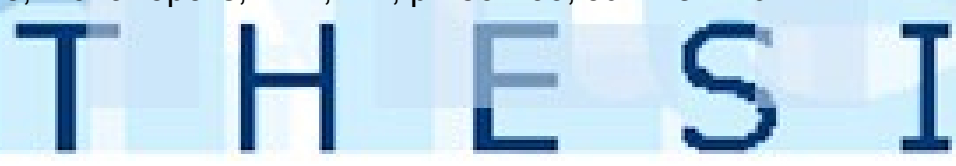
observam algumas famílias ao lembrar que não tinham o hábito, como os demais na comunidade, de plantar árvores junto com os cultivos para fornecer lenha:

Antes aqui era tudo capim melado, hoje tá tudo em mato, os matos aqui eram muito pobres e por isso teve a necessidade de plantar lenha, há 50 anos a preocupação era de ter lenha, meus os avós andavam duas horas para pegar lenha (CAN03).

Apesar do sistema de roça itinerante ser considerado um sistema autossustentável (OLIVEIRA et al., 1994; BERKES et al., 1995), percebe-se que houve um tempo na localidade em que a exploração da terra era intensa devido à alta densidade populacional, e os períodos de pousio não eram respeitados, havendo grande necessidade de plantio de espécies florestais para produção de lenha, já que os estoques florestais nativos não puderam suprir a alta demanda. Baixa densidade populacional e longo tempo de pousio são variáveis que mantêm o sistema tradicional fundamentado em bases sustentáveis (OLIVEIRA et al., 1994).

Com o passar do tempo, a partir da década de 70 , os engenhos de farinha e açúcar passaram a ser monitorados pela vigilância sanitária. As exigências de enquadramento da sua estrutura com base num design industrial inviabilizaram a continuidade dessa atividade em pequena escala, conduzida por pequenos agricultores. Os engenhos de farinha e açúcar tão enraizados culturalmente na população passaram a ser fiscalizados intensamente, incluindo a exigência da apresentação de rótulos com informações nutricionais e registro fiscal nos produtos. Tais exigências não puderem ser implementadas pela falta de orientação técnica, recursos financeiros e infraestrutura para adequação aos requisitos legais. Como resultado, a atividade entrou em colapso, com consequente declínio das oportunidades de geração de renda na localidade. O declínio dos engenhos também foi detectado por Bauer (2012) com aumento do êxodo rural e início da atividade carvoeira.

Outra consequência da diminuição das atividades de engenho foi a falta de alternativas para sobrevivência dos agricultores, ocasionando escassez de mão-deobra para manter os poucos pontos engenhos que restaram. A escassez de mão-deobra está associada ao êxodo rural, que foi muito intenso na região nas décadas de 80 e 90 (Casagrande, 2006), resultado tanto dos períodos de pouco investimento na agricultura familiar no país quanto da desvalorização cultural e social que a agricultura familiar tem enfrentado.

O que se constata é que o aumento do êxodo rural a partir da década de 70 , início de 80 , é resultado das condições macroeconômicas do país nesta década, onde 
o investimento para a agricultura industrial foi uma das diretrizes nacionais e os pequenos agricultores se depararam com a falta de perspectivas na atividade do campo e aumento das atrações na cidade (CASAGRANDE, 2006). Hoje, grande parte da população jovem não permanece no campo, comprometendo a sucessão familiar. Dessa forma, a continuação deste sistema cultural de manejo dos recursos da agrobiodiversidade pode estar comprometida.

Verifica-se a transição nas bases do sistema tradicional ao averiguar-se que dentre as estratégias de condução da roça itinerante no passado e no presente houve mudanças. Há distintas contribuições dessas estratégias para a caracterização do sistema itinerante ao longo do tempo. A análise de ordenamento por meio dos componentes principais que influenciam a caracterização do sistema (com base nas estratégias apresentadas na Figura 2) demonstra que existem dois principais componentes que representam grande parte da variação entre a composição do sistema no passado e no presente. Estes componentes explicam $58,6 \%$ da variação total do manejo praticado no passado e $82 \%$ da variação para o sistema praticado hoje (Tabela 2).

Tabela 2. Autovalores e contribuição da variação para cada componente principal em análise de PCA baseada em oito estratégias utilizadas no passado e no presente por agricultores de duas microbacias hidrográficas de Três Riachos, na realização do manejo de roça itinerante em Biguaçu-SC. (CP= Componente principal)

\begin{tabular}{ccc|ccc}
\hline \multicolumn{3}{c|}{ Passado } & \multicolumn{3}{c}{ Presente } \\
\hline CP & Autovalor & \% variância & CP & Autovalor & \% variância \\
\hline 1 & 0,307132 & $\mathbf{3 1 , 5 7 1}$ & 1 & 0,444368 & $\mathbf{4 8 , 0 9 6}$ \\
2 & 0,263274 & $\mathbf{2 7 , 0 6 3}$ & 2 & 0,313878 & $\mathbf{3 3 , 9 7 3}$ \\
3 & 0,22455 & 23,082 & 3 & 0,105878 & 11,46 \\
4 & 0,128064 & 13,164 & 4 & 0,0597894 & 6,4713 \\
5 & 0,0329077 & 3,3827 & 5 & 0 & 0 \\
6 & 0,0168982 & 1,737 & 6 & 0 & 0 \\
\hline
\end{tabular}

$\mathrm{Na}$ diferenciação do sistema praticado ao longo do tempo percebe-se que houve mudança no uso das estratégias de condução (Tabela 3). No passado as práticas que mais contribuíram para a diferenciação do sistema praticado no eixo 1 estão associadas ao plantio de espécies da flora brasileira (plantio outras nativas,

R. Inter. Interdisc. INTERthesis, Florianópolis, v.11, n.2, p.183-203, Jul./Dez. 2014

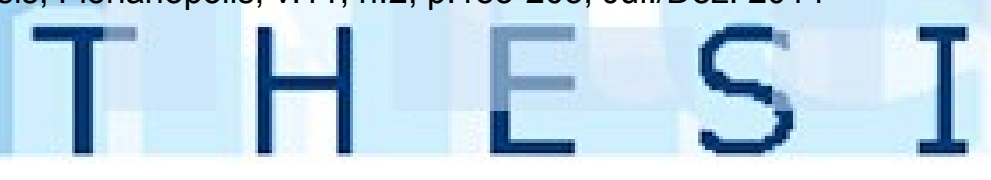


plantio Bracatinga e plantio Ingá). No eixo 2 tanto o plantio de ingá continua influenciando o agrupamento da população, quanto a prática da promoção da regeneração natural junto à prática da capina seletiva apresentam contribuição para essa diferenciação.

Nota-se que para o momento presente (Tabela 3), a variável do eixo $1 \mathrm{com}$ maior contribuição para diferenciação do sistema foi o plantio de espécies nativas (outras nativas e bracatinga) juntamente com a introdução da capina química. Já para o eixo 2, a variável de maior contribuição para diferenciação do sistema foi a introdução do eucalipto. A introdução do eucalipto no sistema, o abandono do plantio de ingá e a diminuição da capina seletiva representam assim a grande variação nas estratégias praticadas dentro do sistema de roça itinerante ao longo do tempo.

Tabela 3. Escores das variáveis analisadas para dois componentes principais calculados em análise de PCA baseada em oito estratégias utilizadas no passado e no presente por agricultores de duas microbacias hidrográficas de Três Riachos, na realização do manejo de roça itinerante em Biguaçu-SC

\begin{tabular}{lcccc}
\hline \multicolumn{1}{c}{ Práticas } & \multicolumn{2}{c}{ Passado* $^{*}$ Presente $^{* *}$} \\
& Eixo1 & Eixo 2 & Eixo 1 & Eixo 2 \\
\hline Plantio Eucalipto & 0 & 0 & $-0,05705$ & $\underline{0,8553}$ \\
Plantio outras nativas & 0,3894 & 0,1483 & $\underline{0,5654}$ & 0,4461 \\
Plantio Bracatinga & $\underline{0,7106}$ & 0,0644 & $\underline{0,5797}$ & $-0,2389$ \\
Plantio Ingá & 0,4780 & $\underline{-0,6623}$ & $6,709^{\mathrm{e}}-18$ & $1,102^{\mathrm{e}-18}$ \\
Regeneração natural & 0,2457 & 0,5737 & 0 & 0 \\
Capina seletiva & 0,1749 & 0,4517 & 0 & 0 \\
Capina química & 0 & 0 & $\underline{0,5839}$ & $-0,1113$ \\
Nenhuma & $-0,1549$ & 0,04485 & 0 & 0 \\
\hline
\end{tabular}

A prática de promover e permitir a regeneração natural da área não influenciou na diferenciação do sistema quando comparado os dois períodos avaliados, demonstrando que a condução da regeneração natural ainda é uma prática realizada pela população local, da mesma forma como ocorria no passado. Esse fato é de fundamental importância, pois mesmo sendo substituído o recurso florestal que fornecerá lenha desejada, o sistema conta com a mesma lógica de regeneração florestal natural, importante constatação do ponto de vista ecológico. Ou seja, a R. Inter. Interdisc. INTERthesis, Florianópolis, v.11, n.2, p.183-203, Jul./Dez. 2014

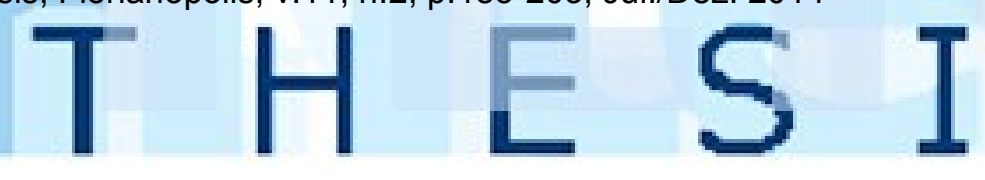


maioria das famílias participantes da pesquisa ainda utiliza a regeneração natural como elemento de condução do sistema após o plantio agrícola, apesar do cultivo do eucalipto.

Contudo, com o cultivo desta espécie exótica não haverá cultivo agrícola antes que seja alcançado o seu ciclo produtivo, ou seja, em torno de 12 anos - tido pelos informantes como ponto de corte ideal para produção de carvão. Apesar disso, a duração desse ciclo se assemelha ao tempo de pousio, ao qual as roças baseadas na mata nativa são submetidas, podendo assim haver a recuperação da fertilidade do solo caso não haja eliminação da regeneração natural. $O$ mesmo padrão foi encontrado por Bauer (2012) salientando que esse processo vem resultando "numa silenciosa invasão da paisagem". Ela apresenta a transformação da paisagem com o tempo, demonstrando como a expansão do plantio de eucaliptais (considerados reflorestamentos) tem realmente sido expressiva.

Essas mudanças apontam para o quanto as famílias estão alterando as estratégias de manejo ao longo do tempo, estratégias essas que vem sendo agregadas com base em insumos sintéticos (capina química) e espécies florestais que precisam ser adquiridas fora da localidade. Com isso há aumento dos custos de manutenção do sistema e a diminuição da rotatividade na paisagem. Flowers et al. (1982) analisaram populações indígenas brasileiras que também apresentam diferenciações no sistema de manejo, mas estas estão primordialmente ligadas ao tipo e número de cultivos utilizados na fase de agrícola, tempo de queimada e tamanho das áreas suprimidas e não nas estratégias fundamentais de manejo, que aqui incluem a substituição da floresta nativa.

As influências do mundo externo à comunidade influenciam suas tomadas de decisão, principalmente quando estas comunidades apresentam características de populações tradicionais, elas exibem características desta influência em seu modo de vida (DIAMOND, 2012). As mudanças percebidas vão além da adaptação econômica. Elas se aprofundam na adaptação cultural ao tipo de cultivo e características de manejo da floresta. Ambos foram sendo alterados e adaptados às conjunturas da época em que eventos ocorreram. Ambos alcançam hoje o que se vê por meio de um sistema itinerante em transformação para um sistema permanente, que paulatinamente deixa de envolver os recursos florestais nativos e regeneração dos recursos utilizados. Pelo contrário, requer cada vez mais o replantio e a condução "convencional" de cultivos florestais que exigem cuidados outros, diferentemente do

R. Inter. Interdisc. INTERthesis, Florianópolis, v.11, n.2, p.183-203, Jul./Dez. 2014

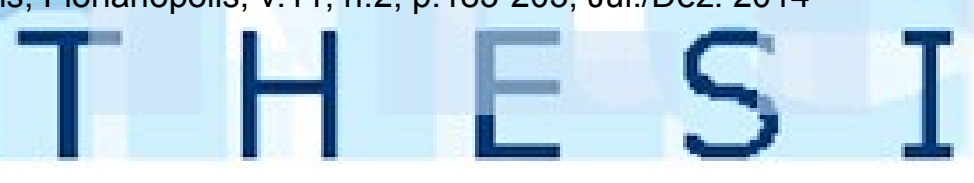


que as florestas nativas promovidas requeriam. Aqui se estabelece a verdadeira reflexão do quanto a atual gestão legal das florestas brasileiras está contribuindo com a sua permanência, continuidade de uso e consequentemente para sua conservação.

\section{CONCLUSÕES}

Conclui-se que mudanças na conjuntura sociopolítica do setor agrícola influenciaram as tomadas de decisão das famílias agricultoras da localidade sobre a manutenção e transformação do sistema de roça itinerante praticado por elas. Essas mudanças puderam ser percebidas nas estratégias de promoção do sistema de manejo que vem sendo praticadas com menor diversidade e inserção de insumos sintéticos, bem como pela migração da população para a cidade e para outras atividades diminuindo a relação com as florestas nativas. Com o abandono e transformação da atividade teme-se pela manutenção das florestas nativas na localidade, uma vez que com a ausência dos agricultores tradicionais no local há possibilidade de destinação da terra para outros usos, muitas vezes não associados à promoção da floresta nativa. A população local apresenta relação direta com os recursos florestais no âmbito cultural, social e econômico, devendo (devendo ou devido?) seu conhecimento e modo de vida serem (serem não parece ser o melhor verbo para ser utilizado na frase, ficou confuso) preservados e protegidos pelos órgãos responsáveis.

R. Inter. Interdisc. INTERthesis, Florianópolis, v.11, n.2, p.183-203, Jul./Dez. 2014
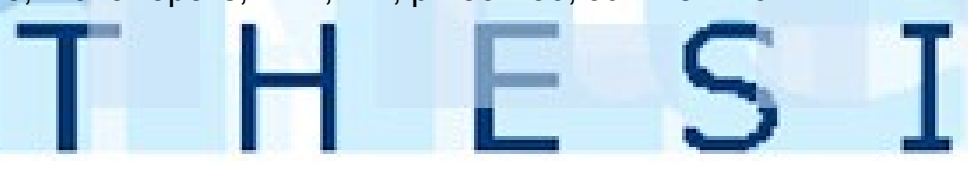


\title{
TRANSFORMATION IN THE TRADITIONAL SWIDDEN AGRICULTURE SYSTEMS IN THE ATLANTIC FOREST OF BRAZILIAN SOUTHERN COAST
}

\begin{abstract}
:
This paper aims to understand the changes in the traditional system of swidden agriculture on the coast of Santa Catarina State over the past four decades. The research was developed by traditional farmers, residents of two watersheds in the municipality of Biguaçu-SC. The sampling unit was the property where the keyinformant selected by the snowball method lies. Semi-structured interviews were conducted, participant observations and guided-tours for data collection. The analysis of data gathered through the Atlas.ti software of descriptive statistics and multivariate analysis of principal components. The data were interpreted based on the historic line of occurrence. The research found that the management performed by the local population is based on periodic driving of agricultural and forestry crops, a system of rotation with fallow periods. The main agricultural crops used were cassava, bananas, maize, coffee and sugarcane, but currently only the cassava has had strong expression. For all phases of the management, farmers had specific knowledge of reading the landscape and forest dynamics. Changes in agricultural policies and management of native forests have directly affected the local system in the watersheds studied. The local population has intrinsic relationship with the native forest resources and their traditional system and way of life must be respected and valued.
\end{abstract}

Keywords: Swidden agriculture. Family agriculture. Secondary forests. Traditional populations. Historical ecology.

\section{TRANSFORMACIONES EN EL SISTEMA TRADICIONAL DE AGRICULTURA ITINERANTE EN EL BOSQUE ATLÁNTICO DE BRASIL}

\section{Resumen:}

Este artículo pretende comprender los cambios en el sistema tradicional de granja itinerante en el litoral de Santa Catarina en las últimas cuatro décadas. La investigación fue desarrollada junto a agricultores tradicionales residentes en dos microcuencas del municipio de Biguaçu-SC. La unidad de muestreo fue la propiedad donde reside el informante clave, seleccionado a través de bola de nieve. Se realizaron entrevistas semiestructuradas, observación-participante y caminata-dirigida para colecta de datos. El análisis de datos fue a través del software Atlas.ti, de estadística descriptiva y análisis multivariante de Componentes Principales. Los datos fueron interpretados en base a la línea histórica de ocurrencia. La investigación diagnosticó que la manipulación realizada por la población local se basa en conducción periódica de cultivos agrícolas y forestales en un sistema de rotación periódica con períodos de descanso. Los principales cultivos agrícolas utilizados fueron mandioca, plátanos, maíz, café y caña de azúcar, pero actualmente sólo la mandioca predomina. En todas las fases del desarrollo de la gestión de manejo los agricultores demuestran tener conocimientos específicos de lectura de la dinámica del paisaje y del bosque. Cambios en las políticas agrícolas y manejo de bosques nativos han afectado directamente el sistema de explotación itinerante en las microcuencas estudiadas. La población local tiene relación muy fuerte con los recursos del bosque nativo, por lo que su estilo de vida debe de ser respetado y el sistema tradicional valorado.

Palabras clave: Granja-de-juego. Agricultura familiar. Bosques secundarios. Poblaciones tradicionales. Ecología histórica. 


\section{REFERÊNCIAS}

ADAMS, C.; MUNARI, L. C.; VLIET, N. V.; MURRIETA, R. S. S.; PIPERATA, B.A.; FUTEMMA, C. PEDROSO Jr., N. N.; TAQUEDA, C. S.; CREVELARO, M. A.; SPRESSOLA-PRADO, V. L. Diversifying incomes and losing landscape complexity in quilombola shifting cultivation communities of the Atlantic Rainforest (Brazil). Human Ecology, 41: 119-137, 2013.

ADAMS, C. As roças e o manejo da Mata Atlântica pelos caiçaras: Uma revisão. Interciência, v.25, n.3. p. 143-150, 2000a.

ADAMS, C. . As Populações Caiçaras e o Mito do Bom Selvagem: a necessidade de uma nova abordagem interdisciplinar. Revista de Antropologia, v. 43, n.1, p. 145-182, $2000 \mathrm{~b}$.

ALEXIADES, M.N.; SHELDON.J.W. Quantitative methods in Ethnobotanical fieldwork. Introduction. 167-171. In: ALEXIADES, M.N. (editor). Selected guidelines for Ethnobotanical research: a field manual. New York: The New York Botanical Garden, 1996.

BALÉE, W. People of the Fallow: A historical ecology of foraging in Lowland South America. In: REDFORD, K.H. e PADOCH, C. (eds). Conservation of Neotropical Forests. New York, Columbia: U press. p.35-57, 1992.

BALEÉ, W. The research program of Historical ecology. Annu. Rev. Anthropol. 35:5.1-5.24, 2006.

BARRELLA, W. et al. As relações entre as matas ciliares os rios e os peixes. In: RODRIGUES, R.R.; LEITÃO FILHO; H.F. (Ed.) Matas ciliares: conservação e recuperação. 2.ed. São Paulo: Editora da Universidade de São Paulo, 2001.

BAUER, E. Mudanças no uso da terra em Biguaçu-SC: Agricultores em permanente processo de adaptação. Dissertação (mestrado em Agroecossistemas) Universidade Federal de Santa Catarina. 96p., 2012.

BERKES, F.; FOLKE, C. e GADGIL, M. Traditional ecological knowledge, biodiversity, resilience and sustainability. In: PERRINGS, C.S., MÄLER, K.G.; FOLKE, C.; HOLLING, C.S. e B.O. JANSSON (eds.). Biodiversity conservation: Problems and policies. Dordrecht, Kluwer Academic Press: pp. 281-300. 1995.

R. Inter. Interdisc. INTERthesis, Florianópolis, v.11, n.2, p.183-203, Jul./Dez. 2014

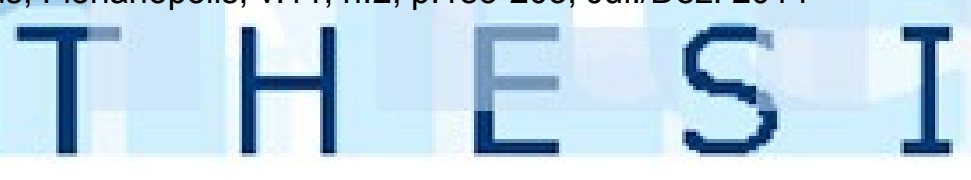


BERNARD, H.R. Research methods in anthropology: qualitative and quantitative approaches. 2a ed., New York: Altamira Press, 1994.

BROOKFIELD, H. e PADOCH, C. Managing biodiversity in spatially and temporally complex agricultural landscapes. p.338-461. In: JARVIS, D. I.; PADOCH, C.; COOPER, H.D. (Eds). Managing biodiversity in agricultural ecosystems. 492p, 2007.

BROWN, D.; SCHRECKENBERG, K. Shifting cultivators as agents of deforestation: assessing the evidence. Natural Resources Perspectives - Overseas Development Institute, n.29, 1-14, 1998.

CAIRNS, M. (Ed) Voices from the forest: integrating indigenous knowledge into sustainable upland farming. RFF Press book: Washington, 2007. $856 \mathrm{p}$.

CASAGRANDE, W.A. Causas da migração rural-urbana na região da Grande Florianópolis; relatos de pesquisa - Síntese regional. Florianópolis: Epagri: CEPA, 2006. 53p.

COLFER, C. J. P.; PELUSO, N.; CHUNG, C.S. Beyond slash and burn: Building on indigenous management of Borneo's Tropical rain forests. Advances in economic Botany, vol. II. Peters, c. M. (Ed.). New York Botanical Garden. 1997, 236p.

CONKLIN, H.C. The study of Shifting Cultivation. Current Antropology, vol.02, $\mathrm{n}^{\circ} 01$, p.27-35, 1961.

COOMES, O.T.; GRIMARD, F.; BURT, G.J. Tropical forests and shifting cultivation: secondary forest fallow dynamics among traditional farmers of the Peruvian Amazon. Ecological Economics 32, 109-124, 2000.

CRIVOS, M.; MARTINÉZ, M.R.; POCHETTINO, M.L.; REMORINI, C.; SY, A. and TEVES, L. Pathways as "signatures in landscape": towards an ethnography of mobility among the Mbya-Guaraní (Northeastern Argentina). Journal of Ethnobiology and Ethnomedicine, 3:2, 2007.

DIAMOND, J. The world until yesterday: What can we learn from traditional societies? Viking: New York, 2012. 499p.

FILHO, A. A. R.; ADAMS, C. MURRIETA, R. S. S. The impacts of shifting cultivation on tropical forest soil: A review. Bol. Mus. Emílio Goeldi. Ciencias Humanas. v.8, n.3, 693-727, 2013.

R. Inter. Interdisc. INTERthesis, Florianópolis, v.11, n.2, p.183-203, Jul./Dez. 2014

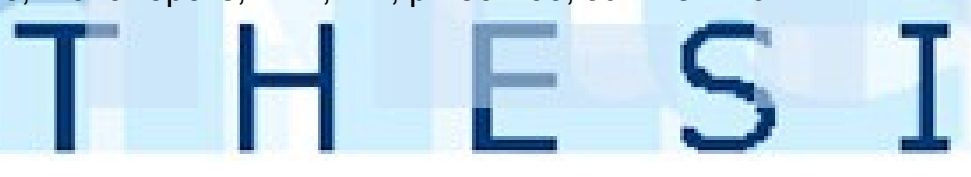


FLOWERS, N.M.; GROSS, D. R.; RITTER, M.L.; WERNER, D. W. Variation in Swidden Practices in Four Central Brazilian Indian Societies. Human Ecology, vol. 10, $\mathrm{n}^{\circ} 2$, p.203-217, 1982.

GARRITY, D. P. Challenges for research and development on improving shifting cultivation systems. P.3-6. In: CAIRNS, M. (Ed) Voices from the forest: integrating indigenous knowledge into sustainable upland farming. RFF Press book: Washington, 2007. 856p.

GUARIGUATA, M. R.; OSTERTAG, R. Neotropical secondary forest succession: changes in structural and functional characteristics. Forest Ecology and Management, 148: 185-206. 2001.

HANAZAKI, N.; TAMASHIRO, J. Y.; LEITÃO-FILHO, H. F.; BEGOSSI, A. Diversity of plant uses in two Caiçara communities from the Atlantic Forest coast, Brazil.

Biodiversity and Conservation, 9: 597-615, 2000.

HANAZAKI, N.; SOUZA, C. V.; RODRIGUES, R.R. Ethnobotany of rural people from the boundaries of Carlos Botelho State Park, São Paulo State, Brazil. Acta bot. bras., 20 (4): 899-909. 2006.

IBGE - Censo Demográfico 2010. Rio de Janeiro: IBGE, 2013. Disponível em: < http://cod.ibge.gov.br/1VFH>. Acesso em: 13 dezembro. 2013.

IBGE - Histórico Cidades. 2013. Santa Catarina-Biguaçu: Inpho graphics. Disponível em: <http://cod.ibge.gov.br/2621A> Acesso em: 13 dezembro. 2013.

JARVIS, D. I.; PADOCH, C.; COOPER, H.D. Biodiversity, agriculture, and ecosystem services. pp1-12. In: JARVIS, D. I.; PADOCH, C.; COOPER, H.D. (Eds). Managing biodiversity in agricultural ecosystems, 2007. 492p.

LUNT, I.D. e SPOONER, P.G. Using historical ecology to understand patterns of biodiversity in fragmented agricultural landscapes. Journal of Biogeography. 32, 1859-1873, 2005.

MAZOYER, M.;ROUDART, L. História das agriculturas no mundo: do neolítico à crise contemporânea. São Paulo: Editora UNESP; Brasília, DF: NEAD, p.129-173. 2010. 
MICHON, G. Domesticating forests: How farmers manage forest resources.

Indonesia: Center for International Forestry Research - The world Agroforestry Centre, 2005. 203p.

MILANESI, L. S.; PERONI, N. REIS, M. S. use of the palm Euterpe edulis Martius in landscapes units managed by migrants of German origin in Southern Brazil. Journal of the Ethnobiology and Ethnomedicine, 9: 47, 2013.

NAKAGAWA, M.; MOMOSE, K.; KISHIMOTO-YAMADA, K.; KAMOI, T.; TANAKA, H.O.; KAGA, M.; YAMASHITA, S.; ITIOKA, T.; NAGAMASU, H.; SAKAI, S.;

NAKASHIZUKA, T. Tree community structure, dynamics, and diversity partitioning in a Bornean tropical forested landscape. Biodiversity Conservation, 22:127-140, 2013.

OLIVEIRA, R.R.; LIMA, D. F.; SAMPAIO, P. D.; SILVA, R. F.; TOFFOLI, D. D. G. Roça caiçara: um sistema "primitivo" autossustentável. Ciência Hoje, v.18 (104), p.44-52, 1994.

PADOCH, C.; PINEDO-VASQUEZ, M. Saving Slash-and-Burn to save biodiversity. Biotropica, 42(5): 550-552, 2010.

ROCHA-SANTOS, L. e TALORA, D.C. Recovery of Atlantic Rainforest areas altered by distinct land-use histories in Northeastern Brazil. Tropical Conservation Science, vol.5 (4): 475-494, 2012.

ROUÉ, M. Novas perspectivas em etnoecologia: "Saberes Tradicionais" e gestão dos recursos naturais. In: DIEGUES, A. C. (org). Etnoconservação: novos rumos para a proteção da natureza nos trópicos. São Paulo: Hucitec. p.67-79, 2000.

SIMINSKI, A.; FANTINI, A.C. Classificação da Mata atlântica do litoral catarinense em estádios sucessionais: ajustando a lei ao ecossistema. Floresta e Ambiente, vol.11, n. 2, p.20-25, 2004.

SIMINSKI, A.; FANTINI, A.C. Roça-de-toco: uso de recursos florestais e dinâmica da paisagem rural no litoral de Santa Catarina. Ciência Rural, v.37, n.3, p.690-696, 2007.

SOEDARSONO, R.; HARTANTI, L. Human impacts on tropical forest dynamics. Vegetatio 121: 41-52, 1995.

SOLÓRZANO, A.; OLIVEIRA, R.R.; GUEDES-BRUNI, R.R. Geografia, história e ecologia: criando pontes para a interpretação da paisagem. Ambiente e Sociedade. V.XII, n.01, p.49-66, 2009.

R. Inter. Interdisc. INTERthesis, Florianópolis, v.11, n.2, p.183-203, Jul./Dez. 2014
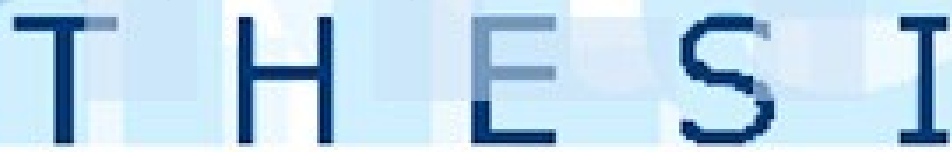
TONGCO, M.D.C. Purposive sampling as a tool for informant Selection. Research e Applications. v.5, p.147-158, 2007.

VIBRANS, A. C.; McROBERTS, R.E.; LINGNER, D.V.; NICOLETTI, A.C.; MOSER, P. Extensão original e remanescentes da Floresta Ombrófila Densa em Santa Catarina. p.25-35. In: VIBRANS, A.C.; SEVEGNANI, L.; GASPER, A. L.; LINGNER, D.V. (Eds). Floresta Ombrófila Densa. Inventário Florístico Florestal de Santa Catarina, v.IV. Blumenau: Edifurb, 2013.

VIETLER,R.B. Métodos antropológicos como ferramenta para estudos em Etnobiologia e Etnoecologia. In: I Seminário de Etnobiologia e Etnoecologia do Sudeste. Rio Claro, São Paulo, SBEE, 2001.

VLIET, N. VAN.; MERTZ, O.; HEINIMANN, A.; LANGANKE, T.; PASCUAL, U.; SCHMOOK, B.; ADAMS, C.; SCHMIDT-VOGT, D.; MESSERLI, P.; LEISZ, S.;CASTELLA, J.C.; JORGENSEN, L.; BIRCH-THOMSEN, T. HETT, C.; BECHBRUNN, T.; ICKOWITZ, A.; VU, C. K.; YASUYUKI, K.; FOX, J.; PADOCH, C.; DRESSLER, $W$ and ZIEGLER, A.D. Trends, drives and impacts of changes in swidden cultivation in tropical forest-agriculture frontiers: A global assessment. Global Environmental Change, 22, 418-429. 2012.

WILLIS, K.J.; GILSON, L.;BRNCIC, T.M. How "Virgin" is virgin rainforests? Science, v.304, p.402-403. 2004. 